Wildenthal, Lora. Review of Kolonialmetropole Berlin. Eine Spurensuc, by Ulrich van der Heyden and Joachim Zeller (eds.). Central European History 38, no. 4 (2005): 661-662.

doi: $10.1017 / \mathrm{S} 000893890000580 \mathrm{X}$.

\title{
Kolonialmetropole Berlin. Eine Spurensuche. Edited by Ulrich van der Heyden and Joachim Zeller. Berlin: Berlin Edition. 2002. Pp. 320. €24.80. ISBN 3-814-80092-3.
}

\author{
Lora Wildenthal, Rice University
}

German colonialism has never been entirely neglected as an object of scholarly study. A great deal of critical work was done in the 1960s and 1970s, and now again the topic is prominent at the German Studies Association, African Studies Association, and in publications in Germany, the United States, and beyond. But anyone engaged in such work, I would wager, has encountered the skepticism of both fellow historians and laypeople who find the entire phenomenon really quite obscure. Kolonialmetropole Berlin is a readable, absorbing demonstration of the fact that traces of the German colonial era are everywhere, if one only cares to look. Richly illustrated, it can be read as an alternative tourist guide to Berlin, and the editors have successfully encouraged their mostly scholarly contributors to speak to a lay audience. Its fifty-five mostly brief entries uncover a layer of Berlin history of which even specialists are not fully aware. While written for a popular audience, it has nothing of the boy's-adventure-story tone of some popular histories of German colonialism published around 1984 for the centenary of the first annexations. It is critical (although authors' viewpoints vary within that range) and not at all condescending to the non-specialist.

This book can also be read by serious students of German history as a survey of sources and questions scholars have uncovered and continue to examine, concerning ethnographic, artistic, political, economic, and other aspects of [End Page 661] German colonialism. And its content ranges well beyond Berlin. Unlike scholarly essay collections and monographs on these topics, here the sources themselves are the main focus. The reader can imagine herself working with them and finding other, similar ones, now that the hunt for them has been demystified. Graduate students (and undergraduates who can read German) can fruitfully browse for paper topics, primary sources, and kinds of questions one can ask about colonial experiences in these pages.

The earliest historical period treated is the seventeenth century, with the West African colonization efforts of the Great Elector Friedrich Wilhelm; a cluster of entries treat the 1880s, including the establishment of or plans for colonial institutions. Advocates and debaters of empire appear, then economic actors and symbols, such as the "Sarotti Moor." The colonial sciences receive extensive treatment, as do film and other fine arts; even the culture of everyday 
life makes an appearance with an entry on the urban "Schreber garden" plots. One of the best sections concerns Africans living in Berlin, during or after the era of formal empire. The important revisionist post-colonial era (1919-1945) receives its own section of entries as well as popping up in other sections, and finally, the concluding entries consider traces of German colonial history in Berlin museums.

Most of the contributors are historians who either occupy academic positions or are active as freelance authors. A few work in film, archives, museums, and development. Some are experts of long standing, such as Hartmut Pogge von Strandmann and Peter Sebald. Most entries draw upon archival and recent secondary sources; a few draw only upon one secondary source, essentially conveying the contents of an existing piece of work via this more popularized format. Even in that case, however, the footnotes show the way forward if the reader wants to learn more, and every entry offers a coherent, stand-alone account of its subject.

The editors' goal was to show the variety and richness of these kinds of materials, and the fact that one constantly thinks of what else might have been included, had space permitted, is an indication of their success. Fortunately, a second volume is to appear in 2005. 